Research Article

\title{
Study on Psycho-social Problems among COVID- I 9 Patients in Tirunelveli District, Tamil Nadu, India
}

Shantaraman Kalyanaraman', Praveena Daya $A^{2}$, Sunitha K ${ }^{3}$, Charles Pon Ruban ${ }^{4}$, Alagesan $S^{5}$

${ }^{1}$ Vice Principal, Government Tirunelveli Medical College, Tirunelveli, Tamil Nadu, India.

${ }^{2,4}$ Assistant Professor, Department of Community Medicine, Government Tirunelveli Medical College, Tirunelveli, Tamil Nadu, India.

${ }^{3}$ Professor, Department of Community Medicine, Government Thoothukudi Medical College, Thoothukudi, Tamil Nadu, India. ${ }^{5}$ Professor, Department of General Medicine, Government Tirunelveli Medical College,Tirunelveli, Tamil Nadu, India.

DOI: https://doi.org/10.24321/0019.5138.202154

\section{I $\quad \mathbf{N} \quad \mathbf{F} \quad \mathbf{O}$}

\section{Corresponding Author:}

Praveena Daya A, Department of Community Medicine, Government Tirunelveli Medical College, Tirunelveli, Tamil Nadu, India.

E-mail Id:

drdayamd@gmail.com

Orcid Id:

https://orcid.org/0000-0001-6249-5190

How to cite this article:

Kalyanaraman S, Praveena Daya A, Sunitha K, Ruban CP, Alagesan S. Study on Psycho-social Problems among COVID-19 Patients in Tirunelveli District, Tamil Nadu, India. J Commun Dis. 2021;53(3):173-180.

Date of Submission: 2021-08-10

Date of Acceptance: 2021-09-21

\section{$\begin{array}{llllllll}\mathbf{A} & \mathbf{B} & \mathbf{S} & \mathbf{T} & \mathbf{R} & \mathbf{A} & \mathbf{C} & \mathbf{T}\end{array}$}

Background: COVID-19 crisis leads to significant changes in routine life, loss of employment, financial crisis, living in isolation, and death of loved ones etc. that can create worry and stress among the people infected with COVID-19. The aim of the study is to estimate the burden of psycho-social problems among COVID-19 patients admitted in a tertiary care institute. A hospital-based cross-sectional study carried out among stable 450 RT-PCR confirmed COVID-19 patients admitted in the COVID ward of Tertiary Care Institute, Tirunelveli, Tamil Nadu, India between August and September 2020.

Materials and Methods: Participants with self-reported pre-existing mental illnesses were excluded. Psycho-social issues of the participants were studied through telephonic conversation using a predesigned questionnaire including DASS 21 scale. Chi-square test was used to test the association between categorical variables. Variables significant in univariate analysis were included for multivariate analysis. P-value < 0.05 was considered to be statistically significant.

Results: Based on DASS21 Scoring, 89 (20\%) had depression, 190 (42\%) were anxious and $53(12 \%)$ were under stress. Patients aged more than 60 years, literate, with risk factors like diabetes mellitus and hypertension were more likely to have one or more psychological conditions.

Conclusion: There is an increased prevalence of psychological morbidities among COVID-19 patients. It warrants the need for a combined action from health care professionals in the early identification of these psychological issues to prevent long term mental health issues among survivors.

Keywords: Stress, COVID-19 Patients, Depression, Anxiety, Stress, Social Stigma 


\section{Introduction}

In January 2020, WHO declared the COVID-19 outbreak to be a Public Health Emergency of International Concern and in March 2020 it was declared to be a Pandemic involving many countries. ${ }^{1}$ World Health Organization, public health authorities and health care personnel all around the world are acting to contain the outbreak. Enormous concerns like significant changes in routine life, loss of employment, financial crisis, living in isolation, lack of physical contact with family, death of loved ones etc. can create stress among the people infected with COVID-19. ${ }^{2}$ Another important factor that can create fear, worry and stress among the patients was the fear of stigmatization or social discrimination for the disease in the community. Several studies have shown the prevalence of stigma towards COVID 19 infected patients. So apart from morbidity and mortality, the disease had caused massive psychological morbidities as evidenced by reports from various studies across countries and in India. ${ }^{3-7}$

The United Nations has insisted that Governments all around the world consider the consequences of mental health seriously and ensure the availability of mental health support services to the needy. ${ }^{8}$ So it is essential for the health care personnel to identify and address the mental health issues to prevent enormous long-term consequences for families, communities and societies. A study was designed to estimate the burden of psycho-social problems among COVID-19 patients admitted to a tertiary care institute.

\section{Materials and Methods}

The study was initiated after obtaining the approval of the Institutional Ethics Committee. It was a hospital-based crosssectional study carried out through telephonic conversation among 450 confirmed COVID-19 patients admitted in the COVID ward of Tirunelveli Medical College Hospital, Tamil Nadu, India between August and September 2020. Although a face-to-face interview is the best method of data collection, yet due to the peak in COVID-19 pandemic cases during that period, telephonic conversation was preferred to reduce exposure to investigators involved in data collection. Inclusion criteria being Nasal swab confirmed COVID-19 adult patients of both genders, who were stable, well oriented to time, place, person and ready to give oral informed consent. Participants with self-reported pre-existing mental illnesses were excluded from the study. The purpose of the study was explained and confidentiality was ensured. The data were collected within one week of hospital admission to ensure uniformity and to reduce recall bias using a semi-structured questionnaire with 3 parts.

The first part was designed to collect demographic characteristics of participants such as age, gender, education, occupation, place of living and marital status.

The second part collected information on COVID-19 disease status and the presence of several risk factors for severe COVID-19 illness. ${ }^{9}$ It also contained questions to address the stigmatisation or social discrimination faced by the participants and their families because of the disease.

The third part was framed to assess the levels of depression, anxiety, and stress of the participants through DASS 21 questionnaire. ${ }^{10}$ It contained 21 items, a set of three selfreport scales designed to measure the emotional states of depression, anxiety and stress. The questionnaire was translated from English to local language, verified, backtranslated, and piloted before initiation of the study.

The participants were asked to rate their experience with each symptom on a 4-point severity scale which ranges from ' 0 ' (does not apply to me) to ' 3 ' (applies to me most of the time). Individual scores of each scale were added up and multiplied by two to get the total score. Based on the total score, severity labels of depression, anxiety and stress were defined as normal, mild, moderate, severe and extremely severe. The scoring pattern of DASS 21 scale is shown in Table 1.

Table I.Scoring Pattern of DASS 2 I Scale

\begin{tabular}{|c|c|c|c|}
\hline Severity Labels & Depression & Anxiety & Stress \\
\hline Normal & $0-4$ & $0-3$ & $0-7$ \\
\hline Mild & $5-6$ & $4-5$ & $8-9$ \\
\hline Moderate & $7-10$ & $6-7$ & $10-12$ \\
\hline Severe & $11-13$ & $8-9$ & $13-16$ \\
\hline Extremely severe & $14+$ & $10+$ & $17+$ \\
\hline
\end{tabular}

\section{Data Entry and Statistical Analysis}

Data collected were analysed using IBM SPSS version $23 .{ }^{11}$ Descriptive analysis was done and categorical variables were expressed in frequency and percentages. For comparisons between groups, Chi-square test or Fisher exact test was used for categorical variables. Kruskal-Wallis $\mathrm{H}$ test was used to determine statistically significant differences between groups based on demographic or clinical characteristics with scores of depression, anxiety and stress. Variables significant in univariate analysis were further analysed using multiple logistic regression to explore the association between various demographic and clinical characteristics with depression, anxiety and stress levels. P-value less than 0.05 (two-sided) was considered to be statistically significant for all comparisons.

\section{Results}

The results of the study involving 450 confirmed, stable COVID-19 patients are presented as follows. The mean age with SD of study participants was $45.7 \pm 18.152$ and it ranges from 18 to 91 years with 230 (51\%) males and 220 (49\%) females. 65 (14.4\%) participants were aged more than 60 years. The participants were asked regarding pre-existing 
mental illnesses and none of the study participants had known or diagnosed mental illnesses and none of them was on any drugs for treating mental health. Based on the residential status, $60 \%$ were from rural and $40 \%$ from urban areas. Demographic characteristics of study participants are presented in Table 2.

Table 2.Demographic Characteristics of Study Participants $(n=450)$

\begin{tabular}{|c|c|c|}
\hline Categories (years) & $\mathbf{N}$ & \%* \\
\hline \multicolumn{3}{|c|}{ Age } \\
\hline $18-30$ & 142 & 31.6 \\
\hline $31-40$ & 74 & 16.4 \\
\hline $41-50$ & 73 & 16.2 \\
\hline $51-60$ & 96 & 21.3 \\
\hline$\geq 61$ & 65 & 14.5 \\
\hline \multicolumn{3}{|c|}{ Gender } \\
\hline Females & 220 & 48.9 \\
\hline Males & 230 & 51.1 \\
\hline \multicolumn{3}{|c|}{ Educational status } \\
\hline Profession or Honours & 22 & 4.9 \\
\hline Graduate/ Post-graduate & 110 & 24.4 \\
\hline High school certificate & 94 & 20.9 \\
\hline Intermediate or Diploma & 66 & 14.7 \\
\hline Middle school certificate & 70 & 15.6 \\
\hline Primary school certificate & 48 & 10.7 \\
\hline Illiterate & 40 & 8.9 \\
\hline \multicolumn{3}{|c|}{ Occupational status } \\
\hline Employed & 181 & 40.2 \\
\hline Unemployed & 269 & 59.8 \\
\hline
\end{tabular}

${ }^{*}$ Column percentages.

With regard to symptoms, 171 (38\%) were asymptomatic and $279(62 \%)$ had one or more symptoms. Among the symptomatic, 203 (45.1\%) reported fever, followed by cough $71(15.8 \%)$, difficulty in breathing $61(13.6 \%)$, loss of smell and taste 11 (2.4\%) and diarrhoea 9 (2\%). 208 (46.2\%) had one or more risk factors and 242 (53.8\%) had no known risk factors for severe illness from COVID-19.

The presence of various risk factors for severe COVID-19 illness among the study participants is presented in Figure 1.

Type II DM, present among 117 (26\%) respondents, followed by hypertension $(75,17 \%)$ were the major underlying disease conditions among the study participants.

Based on DASS 21 scoring, it was found that $89(20 \%)$ had depression, 190 (42\%) were anxious and 53 (12\%) were under stress. Mean scores of depression, anxiety, and stress among them were 4.25 (95\% Cl: 3.78-4.73), 3.55 (95\% Cl:
3.13-3.96), and 4.85 (95\% Cl: 4.38-5.32) respectively. The distribution of levels of depression, anxiety, and stress among the study participants has been presented in Table 3.

Underlying medical conditions like DM, HTN, Cardio-vascular diseases, cancers, immune-compromised state, diseases of the respiratory system, age more than 60 years and risk behaviours like history of smoking, mentioned as risk factors for severe COVID-19 illness were analysed for their association with levels of depression, anxiety, stress and the results are presented in Tables 4 to 6 . "Severe" and "extremely severe" categories were clubbed into a single column due to very less numbers in "extremely severe" category.

It was found that better education status, increasing age, presence of symptoms, and presence of DM were associated with severe levels of depression. Overall, high anxiety scores were observed more among people aged more than 60 years, literates and symptomatic and severe anxiety was observed more among diabetics. With regard to stress, patients less than or equal to 60 years reported moderate and higher levels of stress and overall stress scores were higher among literates, symptomatic and people with DM. Variables that displayed a statistically significant difference $(p<0.05)$ in univariate analysis were further analysed for their association with depression, anxiety, stress using multivariable logistic regression analysis and the results are shown in Table 7.

After adjusting for other variables, the following were significantly associated with levels of depression, anxiety and stress: patients aged more than 60 years were 4 times more likely to exhibit depression and 1.85 times more likely to be anxious than those aged less than or equal to 60 years. The presence of underlying medical conditions like DM was 5 times more likely to be associated with an increased level of depression, 2.91 times related to an increased level of anxiety and 17.21 times more likely to be associated with stress when compared with non-diabetics. The presence of hypertension was significantly associated with increased stress levels and literates are significantly more likely to have depression, anxiety and stress when compared with illiterates. There is no statistically significant difference observed in the levels of depression, anxiety and stress based on gender.

With regard to social stigma, among the 269 currently unemployed participants, 21 (5\%) had lost their job because of the disease, 114 (25.3\%) reported their family had experienced stigma because of their COVID-19 positive status in the neighbourhood. Among the 114, 107 (94\%) reported that their family experienced social avoidance or rejection, 4 mentioned that their family members were denied employment opportunities, 2 were denied house for rent, and 1 family was restricted from getting drinking water in their living place. 


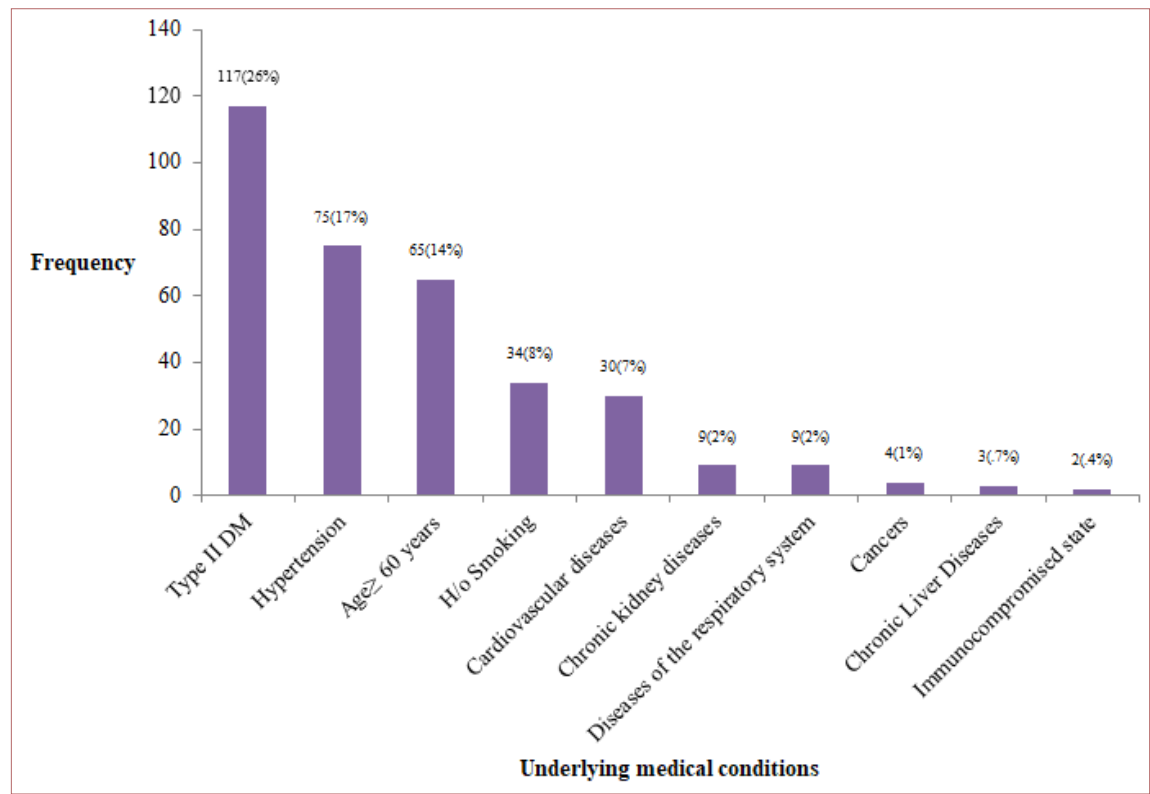

Figure I.Prevalence of Risk Factors for Severe COVID-19 IIIness among Study Participants $(n=450)$

Table 3.Level of Depression, Anxiety and Stress among Study Participants $(n=450)$

\begin{tabular}{|c|c|c|c|c|c|c|}
\hline \multirow{2}{*}{ Severity Labels } & \multicolumn{2}{|c|}{ Depression } & \multicolumn{2}{|c|}{ Anxiety } & \multicolumn{2}{|c|}{ Stress } \\
\hline & Frequency & Percentage* & Frequency & Percentage* & Frequency & Percentage* \\
\hline Normal & 361 & 80.2 & 260 & 57.8 & 397 & 88.2 \\
\hline Mild & 44 & 9.8 & 41 & 9.1 & 22 & 4.9 \\
\hline Moderate & 25 & 5.6 & 105 & 23.3 & 19 & 4.2 \\
\hline Severe & 19 & 4.2 & 41 & 9.1 & 12 & 2.7 \\
\hline Extremely severe & 1 & 0.2 & 3 & 0.7 & - & - \\
\hline Total & 450 & 100.0 & 450 & 100.0 & 450 & 100.0 \\
\hline
\end{tabular}

*Column percentages

Table 4.Association between Risk Factors for Severe COVID-I 9 IIIness and Level of Depression $(n=450)$

\begin{tabular}{|c|c|c|c|c|c|c|}
\hline \multirow{2}{*}{ Risk factors } & \multicolumn{4}{|c|}{ Level of Depression } & \multirow{2}{*}{$\begin{array}{c}X^{2} \\
\text { value }\end{array}$} & \multirow{2}{*}{$\begin{array}{c}\mathbf{P} \\
\text { value }\end{array}$} \\
\hline & Normal N (\%)* & Mild N (\%)* & Moderate N (\%)* & Severe $\mathbf{N}(\%)^{*}$ & & \\
\hline Age $\leq 60$ years & $324(41)$ & $37(20)$ & $16(64)$ & $8(16)$ & \multirow{2}{*}{48.2} & \multirow{2}{*}{$<0.001$} \\
\hline Age $>60$ years & $37(59)$ & $7(80)$ & $9(36)$ & $12(84)$ & & \\
\hline Literate & $338(94)$ & $39(20)$ & $21(84)$ & $2(58)$ & \multirow{2}{*}{65.79} & \multirow{2}{*}{0.001} \\
\hline Illiterate & $23(7)$ & $5(11)$ & $4(16)$ & $8(42)$ & & \\
\hline Asymptomatic & $148(41)$ & $9(21)$ & $10(40)$ & $4(20)$ & \multirow{2}{*}{9.91} & \multirow{2}{*}{0.019} \\
\hline Symptomatic & $213(59)$ & $35(80)$ & $15(60)$ & $16(80)$ & & \\
\hline Without DM & $287(80)$ & $31(70)$ & $12(48)$ & $3(16)$ & \multirow{2}{*}{50.93} & \multirow{2}{*}{$<0.001$} \\
\hline With DM & $74(20)$ & $13(30)$ & $13(52)$ & $17(84)$ & & \\
\hline Without HTN & $308(85)$ & $37(84)$ & $21(84)$ & $9(42)$ & \multirow{2}{*}{24.5} & \multirow{2}{*}{0.001} \\
\hline With HTN & $53(15)$ & $7(16)$ & $4(16)$ & $11(58)$ & & \\
\hline Without CVS disease & $340(94)$ & $42(96)$ & $24(96)$ & $14(74)$ & \multirow{2}{*}{18.52} & \multirow{2}{*}{0.003} \\
\hline With CVS disease & $21(6)$ & $2(4)$ & $1(4)$ & $6(26)$ & & \\
\hline
\end{tabular}

${ }^{*}$ Column percentages, $\mathrm{P}$ value $<0.05$ was considered to be statistically significant. 
Table 5.Association between Risk Factors for Severe COVID- I 9 IIIness and Level of Anxiety

\begin{tabular}{|c|c|c|c|c|c|c|}
\hline \multirow{2}{*}{ Risk Factors } & \multicolumn{4}{|c|}{ Level of Anxiety } & \multirow{2}{*}{$\begin{array}{c}X^{2} \\
\text { value }\end{array}$} & \multirow{2}{*}{$\begin{array}{c}P \\
\text { value }\end{array}$} \\
\hline & Normal N (\%)* & Mild N (\%)* & Moderate N (\%)* & Severe N (\%)* & & \\
\hline Age $\leq 60$ years & $236(91)$ & $36(88)$ & $85(81)$ & $28(63)$ & \multirow{2}{*}{24.79} & \multirow{2}{*}{$<0.001$} \\
\hline Age $>60$ years & $24(9)$ & $5(12)$ & 20 (19) & $16(37)$ & & \\
\hline Literate & $245(94)$ & $38(93)$ & $88(84)$ & $39(88)$ & \multirow{2}{*}{10.49} & \multirow{2}{*}{0.014} \\
\hline Illiterate & $15(6)$ & $3(7)$ & $17(16)$ & $5(12)$ & & \\
\hline Asymptomatic & $117(45)$ & $13(32)$ & $31(30)$ & $10(24)$ & \multirow{2}{*}{12.86} & \multirow{2}{*}{0.004} \\
\hline Symptomatic & $143(55)$ & $28(68)$ & $74(70)$ & $32(76)$ & & \\
\hline Without DM & $216(83)$ & $34(83)$ & $68(65)$ & $15(32)$ & \multirow{2}{*}{53.91} & \multirow{2}{*}{$<0.001$} \\
\hline With DM & $44(17)$ & $7(17)$ & $37(35)$ & $29(68)$ & & \\
\hline Without HTN & $230(89)$ & $35(85)$ & $80(76)$ & $30(70)$ & \multirow{2}{*}{16.17} & \multirow{2}{*}{0.002} \\
\hline With HTN & $30(11)$ & $6(15)$ & $25(24)$ & $14(30)$ & & \\
\hline Without CVS disease & $250(96)$ & $38(93)$ & $96(91)$ & $36(80.5)$ & \multirow{2}{*}{13.34} & \multirow{2}{*}{0.003} \\
\hline With CVS disease & $10(4)$ & $3(7)$ & $9(9)$ & $8(19.5)$ & & \\
\hline
\end{tabular}

*Column percentages.

Table 6.Association between Risk Factors for Severe COVID-I9 IIIness and Level of Stress among Study Participants $(n=450)$

\begin{tabular}{|c|c|c|c|c|c|c|}
\hline \multirow{2}{*}{ Risk factors } & \multicolumn{4}{|c|}{ Level of stress } & \multirow{2}{*}{$\begin{array}{c}X^{2} \\
\text { value }\end{array}$} & \multirow{2}{*}{$\begin{array}{c}\mathbf{P} \\
\text { value }\end{array}$} \\
\hline & Normal N (\%)* & Mild N (\%)* & Moderate N (\%)* & Severe N (\%)* & & \\
\hline Age $\leq 60$ years & $350(88)$ & $16(73)$ & $13(68)$ & $6(50)$ & \multirow{2}{*}{21.9} & \multirow{2}{*}{$<0.001$} \\
\hline Age $>60$ years & $47(12)$ & $6(27)$ & $6(32)$ & $6(50)$ & & \\
\hline Literate & $367(92)$ & $22(100)$ & $14(74)$ & $7(58)$ & \multirow{2}{*}{26.06} & \multirow{2}{*}{$<0.001$} \\
\hline Illiterate & $30(8)$ & $0(0)$ & $5(26)$ & $5(42)$ & & \\
\hline Asymptomatic & $167(42)$ & $2(9)$ & $0(0)$ & $2(17)$ & \multirow{2}{*}{24.55} & \multirow{2}{*}{$<0.001$} \\
\hline Symptomatic & $230(58)$ & $20(91)$ & $19(100)$ & $10(83)$ & & \\
\hline Without DM & $317(80)$ & $13(59)$ & $3(16)$ & $0(0)$ & \multirow{2}{*}{94.39} & \multirow{2}{*}{$<0.001$} \\
\hline With DM & $80(20)$ & $9(41)$ & $16(84)$ & $12(100)$ & & \\
\hline Without HTN & $355(89.4)$ & $11(50)$ & $2(10.5)$ & $7(58)$ & \multirow{2}{*}{106.1} & \multirow{2}{*}{$<0.001$} \\
\hline With HTN & $42(10.6)$ & $11(50)$ & $17(89.5)$ & $5(42)$ & & \\
\hline Without CVS disease & $373(94)$ & $20(91)$ & $19(100)$ & $8(67)$ & \multirow{2}{*}{15.53} & \multirow{2}{*}{0.001} \\
\hline With CVS disease & $24(6)$ & $2(9)$ & $0(0)$ & $4(33)$ & & \\
\hline
\end{tabular}

*Column percentages.

Table 7.Multiple Logistic Regression Analysis Predicting the Association between Risk Factors for Severe COVID- I 9 IIIness and Depression, Anxiety, and Stress $(n=450)$

\begin{tabular}{|c|c|c|c|c|c|c|}
\hline \multirow{2}{*}{ Variables } & \multicolumn{2}{|c|}{ Depression } & \multicolumn{2}{c|}{ Anxiety } & \multicolumn{2}{c|}{ Stress } \\
\cline { 2 - 7 } & OR [95\% Cl] & P value & OR [95\% CI] & P value & OR [95\% CI] & P value \\
\hline Literate & $2.86[1.16-7.02]$ & 0.022 & $2.1[1.03-2.66]$ & 0.039 & $5.69[1.80-17.98]$ & 0.003 \\
\hline Age $>60$ years & $4.19[2.01-8.72]$ & 0.000 & $1.85[1.03-3.32]$ & 0.039 & $1.34[.53-3.36]$ & 0.524 \\
\hline Diabetes mellitus & $5.06[2.40-10.68]$ & 0.000 & $2.91[1.78-4.74]$ & 0.000 & $17.21[4.87-60.68]$ & 0.000 \\
\hline Hypertension & $0.97[0.43-2.20]$ & 0.951 & $1.47[.83-2.61]$ & 0.181 & $8.41[3.17 .1-22.34]$ & 0.000 \\
\hline
\end{tabular}




\section{Discussion}

COVID-19 pandemic made the public face challenges that may be stressful, overwhelming and can cause strong emotions in the lives of adults and children. Public health actions such as social distancing are necessary to reduce the transmission of COVID-19 but they can make people feel isolated, lonely and can lead to stress and anxiety. The current study has found a prevalence of $20 \%$ depression, $42 \%$ anxiety and $12 \%$ stress among the study participants. Similar mental health issues have been identified from studies done in various parts of the world. A crosssectional study by Htun YM et al. in Myanmar found a $38.7 \%$ prevalence of depressive symptoms in COVID-19 patients..$^{12} \mathrm{~A}$ study by Moayed MS et al. among 221 patients with COVID-19 infection in Iran showed a high prevalence of "extremely severe" depression, anxiety and severe stress as $54.29 \%, 97.29 \%$ and $46.61 \%$ respectively. ${ }^{6}$ Hasan MJ et al. studied the mental health of COVID-19 patients and found an overall prevalence of depression and anxiety as $55.7 \%$ and $87.3 \%$ in Bangladesh. ${ }^{13}$ Retrospective cohort studies of 62,354 COVID-19 cases among the USA COVID-19 survivors by Taquet $\mathrm{M}$ et al. found that they are at an increased risk of psychiatric sequelae. ${ }^{14}$

Fear about the cure or prognosis of disease, restricted movements, lack of physical contact with family, temporary loss of job, and fear about social discrimination can lead to depression, stress, anxiety among the people affected with the disease that is evidenced from this study. Learning to cope with these mental health conditions in a healthy way can help the people affected to lead a normal life. Getting involved in daily activities, spending time in recreational activities like listening to music, reading etc. getting connected to loved ones through phone calls or video calls can keep the stress away. People should be advised to seek information related to COVID only from reliable websites like the Ministry of Health and Family Welfare (MoHFW).

COVID-19 can affect anyone and the symptoms of the disease may range from mild to severe illness. Severe illness due to COVID-19 was defined as hospitalization, admission to the ICU, intubation or mechanical ventilation or death. Some people may be more likely to develop severe illness as compared to others because of the presence of few factors or medical conditions that increase their risk. These are commonly called "risk factors" that include diabetes mellitus (type 1 and 2), hypertension, chronic kidney disease, COPD (chronic obstructive pulmonary disease), heart conditions such as heart failure, coronary artery disease or cardiomyopathies, immunocompromised state, obesity, pregnancy, smoking, use of corticosteroid or other immune weakening medicines. ${ }^{9}$

In the present study among the 450 participants, 117 (26\%) have Type II DM followed by hypertension 75 (17\%) and cardiovascular diseases $30(7 \%)$ respectively. The presence of DM was significantly associated with the presence of depression, anxiety, and stress, and hypertension was associated with the presence of stress in this study. The current study also showed higher levels of depression, anxiety, and stress among literates. Several studies have shown that the risk of ICU admission and mortality may be more among people with comorbidities like diabetes when compared with others. People who are literate and with comorbidities like diabetes or hypertension may be more aware of such facts or evidence and may be worried about the prognosis of the disease when compared with others. Zhou F et al. among 191 COVID-19 patients in China, reported that 91 (48\%) patients had comorbidities, hypertension being most common $(58,30 \%)$, followed by diabetes $(36,19 \%)$ and coronary heart disease $(15$, $8 \%) .{ }^{15}$ They also reported that people with comorbidities experience more fear regarding disease prognosis or fatality. The current study identified no significant difference among male and female gender in the level of mental health morbidities observed. Contrary to this, a study by Hurissi E et al. among Saudi Arabian adults showed females are significantly at higher risk for depression and anxiety due to COVID-19 disease compared to males. ${ }^{16}$

Social stigma is defined as discrimination against a particular group of people, a place, or a nation in the form of a negative attitude. ${ }^{17}$ Public health emergencies such as COVID-19 pandemic are stressful situations for people and communities. Fear, confusion, anxiety along with a lack of knowledge about the new disease can lead to social stigma. Discrimination may be in the form of social avoidance or rejection, problems associated with accessing healthcare, housing, employment, education, verbal abuse, physical violence etc. The current study had also notified the presence of similar discriminative behaviours among the communities for COVID-19 disease.

The presence of social stigma may hamper health care activities in various ways. People may hide the illness to avoid discrimination leading to delayed health-seeking behaviours. People may present only at later stages of the disease leading to late treatment initiation and may lead to poor prognosis of the disease. Stigma may also discourage people to adopt healthy behaviours that can lead to disease transmission among the population. Discriminatory behaviours can affect the people who are suffering from the disease, their caregivers, family and community. ${ }^{18} \mathrm{Few}$ studies have shown the presence of social discrimination for COVID-19 disease among the population. So it is vital to address the stigma for COVID-19. Creating awareness in the community regarding the causation, transmission, prevention of disease can reduce the stigma prevalent for the disease to a major extent. World Health 
Organization (WHO) $)^{19}$ and Centers for Disease Control (CDC) have provided various recommendations for coping with stress during the COVID-19 pandemic. $^{20}$

\section{Conclusion}

Public health emergencies may cause fear, worry, stress among the general community and it may be worse among the affected population. The current study found out an increased prevalence of psychological morbidities among stable COVID-19 patients. Findings from this study highlight the need for immediate and combined action from the health care professionals in early identification of these psychological issues to prevent short term, medium, or long term mental health issues among survivors. There is a need of an integrated systematic approach for early screening and identification of these issues not only in the health care settings but also in the community through an effective outreach system. Front line health care workers need to be trained and skilled to provide effective mental health care services to enable patients to have a better capacity to fulfil their social roles.

\section{Recommendations}

Screening for Mental Health illness among COVID-19 affected patients should be integrated into the primary health care system for early identification and continuity of services. Home visits can be arranged for patients who are unable to visit the hospitals. Liaison with NGOs and volunteers in the community can help in ensuring a regular supply of medications at the patients' doorstep. The use of IEC materials to spread accurate facts on COVID-19 related mental health issues and availability of health care services for the same through print, digital and social media platforms can help people in need. Caregivers of COVID-19 patients can be educated to identify the mental health issues at an earlier stage for prompt treatment. General public should be educated and encouraged to utilise the tele-consultation services offered by the Government health system for early health-seeking for mental health issues.

\section{Limitations}

Being a cross-sectional study, the study has its own limitations. Data were collected at a single point in time and so long term consequences of these mental health issues could not be identified. Due to the high prevalence of stigma for mental health issues in the community, study participants may be reluctant to reveal their true experiences or behaviours which can lead to social desirability bias to some extent. Mental health consequences due to COVID-19 among patients with pre-existing mental illnesses were not addressed in this study. Future long-term research focusing on investigating the association between specific co-morbidities and mental health morbidities are needed to create evidence-based health care interventions for future public health emergencies.

\section{Acknowledgement: None \\ Funding: None}

Conflict of Interest: None

\section{References}

1. World Health Organization [Internet]. WHO DirectorGeneral's opening remarks at the media briefing on COVID-19; 2020 [cited 2021 Feb 10]. Available from: https://www.who.int/director-general/speeches/ detail/who-director-general-s-opening-remarks-atthe-media-briefing-on-covid-19---11-march-2020

2. World Health Organization [Internet]. Mental health \& COVID-19; 2021 [cited 2021 Sep 11]. Available from: https://www.who.int/teams/mental-health-andsubstance-use/covid-19

3. Khademian F, Delavari S, Koohjani Z, Khademian Z. An investigation of depression, anxiety, and stress and its relating factors during COVID-19 pandemic in Iran. BMC Public Health. 2021 Feb;21(1):275. [PubMed] [Google Scholar]

4. Al Omari O, Al Sabei S, Al Rawajfah O, Abu Sharour L, Aljohani K, Alomari K, Shkman L, Al Dameery K, Saifan A, Al Zubidi B, Anwar S, Alhalaiqa F. Prevalence and predictors of depression, anxiety, and stress among youth at the time of COVID-19: An online crosssectional multicountry study. Depress Res Treat. 2020 Oct;2020:8887727. [PubMed] [Google Scholar]

5. Alamri HS, Algarni A, Shehata SF, Al Bshabshe A, Alshehri $\mathrm{NN}$, ALAsiri AM, Hussain AH, Alalmay AY, Alshehri EA, Alqarni Y, Saleh NF. Prevalence of depression, anxiety, and stress among the general population in Saudi Arabia during Covid-19 pandemic. Int J Environ Res Public Health. 2020 Dec;17(24):9183. [PubMed] [Google Scholar]

6. Moayed MS, Vahedian-Azimi A, Mirmomeni G, RahimiBashar F, Goharimoghadam K, Pourhoseingholi MA, Abbasi-Farajzadeh M, Hekmat M, Sathyapalan T, Guest PC, Sahebkar A. Depression, anxiety, and stress among patients with COVID-19: A cross-sectional study. Adv Exp Med Biol. 2021;1321:229-36. [PubMed] [Google Scholar]

7. Verma S, Mishra A. Depression, anxiety, and stress and socio-demographic correlates among general Indian public during COVID-19. Int J Soc Psychiatry. 2020 Dec;66(8):756-62. [PubMed] [Google Scholar]

8. United Nations [Internet]. Policy Brief: COVID-19 and the Need for Action on Mental Health; 2020 [cited 2021 Sep 1]. Available from: https://unsdg.un.org/ sites/default/files/2020-05/UN-Policy-Brief-COVID- 
19-and-mental-health.pdf

9. Centers for Disease Control and Prevention [Internet]. People with certain medical conditions; [cited 2020 Sep 10]. Available from: https://www.cdc.gov/ coronavirus/2019-ncov/need-extra-precautions/ people-with-medical-conditions.html

10. Lovibond SH, Lovibond PF. Manual for the depression anxiety \& stress scales [Internet]. 2nd ed. Sydney: Psychology Foundation; 1995. Available from: https:// www.bristol.ac.uk/media-library/sites/sps/documents/ c-change/dass.pdf

11. IBM Corp. IBM SPSS Statistics for Windows. Version 23.0. Armonk, NY: IBM Corp; 2015.

12. Htun YM, Thiha $K$, Aung $A$, Aung NM, Oo TW, Win PS, Sint NH, Naing KM, Min AK, Tun KM, Hlaing K. Assessment of depressive symptoms in patients with COVID-19 during the second wave of epidemic in Myanmar: A cross-sectional single-center study. PLoS One. 2021 Jun;16(6):e0252189. [PubMed] [Google Scholar]

13. Hasan MJ, Tabssum T, Ambia NE, Zaman MS, Rahman M, Khan AS. Mental health of the COVID-19 patients in Bangladesh. Mymensingh Med J. 2021 Jan;30(1):18995. [PubMed] [Google Scholar]

14. Taquet M, Luciano S, Geddes JR, Harrison PJ. Bidirectional associations between COVID-19 and psychiatric disorder: retrospective cohort studies of 62354 COVID-19 cases in the USA. Lancet Psychiatry. $2021 \mathrm{Feb} ; 8(2): 130-40$. [PubMed] [Google Scholar]

15. Zhou F, Yu T, Du R, Fan G, Liu Y, Liu Z, Xiang J, Wang Y, Song B, Gu X, Guan L, Wei Y, Li H, Wu X, Xu J, Tu S, Zhang $\mathrm{Y}$, Chen $\mathrm{H}, \mathrm{Cao} \mathrm{B}$. Clinical course and risk factors for mortality of adult inpatients with COVID-19 in Wuhan, China: a retrospective cohort study. Lancet. 2020 Mar;395(10229):1054-62. [PubMed] [Google Scholar]

16. Hurissi E, Abu-jabir E, Mohammed A, Mahnashi M, Alharbi S, Alharbi A, Alnaami A, Alameer E, Alahmar A, Alhazmi A. Assessment of new-onset depression and anxiety associated with COVID-19. Middle East Curr Psychiatry. 2021;28(1):33. [Google Scholar]

17. Ministry of Health and Family Welfare [Internet]. Social stigma and COVID-19. National Health Portal of India; [cited 2020 Sep 21]. Available from: https://www.nhp. gov.in/healthlyliving/social-stigma-and-covid-19

18. World Health Organization [Internet]. Social stigma associated with COVID-19. A guide to preventing and addressing social stigma; 2020 [cited 2020 Oct 15]. Available from: https://www.who.int/docs/defaultsource/coronaviruse/covid19-stigma-guide.pdf

19. World Health Organization [Internet]. Doing What Matters in Times of Stress; 2020 [cited Oct 11]. Available from: https://www.who.int/publications/i/item/97
89240003927?gclid=CjOKCQjwkIGKBhCXARIsAINMi olx1y6-jkfW8qbFB9aQDuqbCCewuXe19Znek8szXZ4 KT-HbOhyJ91gaAgoiEALw_wcB

20. Centers for Disease Control and Prevention [Internet]. Coping with stress; [cited 2020 Sep 20]. Available from: https://www.cdc.gov/coronavirus/2019-ncov/dailylife-coping/managing-stress-anxiety.html 